\title{
Pendidikan Inklusi Sebagai Solusi Pendidikan Untuk Semua (Penerapan Pendidikan Inklusi di SDN Bromantakan 56 Surakarta)
}

\author{
Serla Kusuma Arum ${ }^{(1)}$, Herry Widyastono ${ }^{(2)}$, Sunardi ${ }^{(2)}$ \\ Pendidikan Luar Biasa Universitas Sebelas Maret Surakarta \\ serlakusuma@student.uns.ac.id ${ }^{(1)}, \underline{\text { herrywidyastono@staff.uns.ac.id }}^{(2)}$, sunardi.ipuns @ gmail.com $^{(3)}$
}

\begin{abstract}
ABSTRAK
Penelitian ini bertujuan untuk mendeskripsikan dan menganalisis penerapan pendidikan inklusi di SDN Bromantakan 56 Surakarta. Metode penelitian yang digunakan adalah pendekatan kualitatif dengan jenis kualitatif studi kasus. Teknik pengumpulan data yang digunakan adalah wawancara mendalam, observasi, dan studi dokumentasi. Teknik analisis data menggunakan teknik analisis interaktif dengan tahapan analisis dimulai dari pengumpulan data, reduksi data, penyajian data, verifikasi dan penarikan kesimpulan. Hasil penelitian ini merupakan kajian terkait penerapan pendidikan inklusi di SDN Bromantakan 56 Surakarta, meliputi landasan penyelenggaraan pendidikan inklusi, kurikulum yang digunakan, pendidik dan tenaga kependidikan,sarana dan prasarana pendidikan inklusi, sistem penerimaan $\mathrm{ABK}$, pengelolaan kegiatan belajar mengajar, proseder penilaian serta keadaan lingkungan sekolah inklusi. Dalam pelaksanaan pendidikan inklusi di SDN Bromantakan 56 Surakarta masih terkendala dengan belum adanya kurikulum khusus untuk ABK, sekolah menggunakan kurikulum 2013 dengan modifikasi untuk mengakomodasi ABK yang bersekolah disana.
\end{abstract}

Kata Kunci : : Pendidikan Inklusi, SDN Bromantakan 56 Surakarta

\begin{abstract}
This study was intended to find out and analyzed the application of inclusive education in SDN Bromantakan 56 Surakarta. The methods of the research used a qualitative approach with a qualitative case study. The data were collected by interviews, observation, and documentary studies. The data were analyzed using interactive patterns of data analysis, the stages of analysis starting from data collection, data reduction, data presentation, verification and conclusion. The results of this study are studies related to the application of inclusive education in SDN Bromantakan 56 Surakarta, including the foundation of the implementation of inclusive education, curriculum used, educators and education personnel, inclusive education facilities and infrastructure, acceptance system, management of teaching and learning activities, assessment procedures and school environment. The implemention inclusive education in SDN Bromantakan 56 Surakarta is still constrained by the absence of a special curriculum for spesial children, schools used curriculum 2013 with modifications to accommodate spesial children who attend school there.
\end{abstract}

Keywords : Inclusive Education, SDN Bromantakan 56 Surakarta 
Arum Serla K, Widyastono H, Sunardi : Pendidikan Inklusi Sebagai Solusi Pendidikan Untuk Semua (Penerapan Pendidikan Inklusi di SDN Bromantakan 56 Surakarta)

\section{PENDAHULUAN}

\section{Latar Belakang}

Pendidikan memiliki peran yang sangat penting dalam membentuk kualitas suatu bangsa. Dalam Undang-Undang No. 20 Tahun 2003 pasal I ayat I tentang Sistem Pendidikan Nasional, dinyatakan pendidikan adalah usaha sadar dan terencana untuk mewujudkan suasana belajar dan proses belajar agar peserta didik dapat secara aktif membangun potensi dirinya untuk memiliki kekuatan spiritual keagamaan, pengendalian diri, kepribadian, kecerdasan, akhlak mulia serta keterampilan yang diperlukan dirinya, masyarakat, bangsa dan negara. Berdasarkan hal tersebut, pendidikan merupakan hak bagi setiap warga Indonesia dan negara harus menjamin keberlangsungan jalannya proses pendidikan tersebut. Guna mewujudkan hak pendidikan bagi setiap warganya, pemerintah mengadakan berbagai program pendidikan, salah satunya adalah pendidikan inklusi. Peraturan Menteri Pendidikan Nasional (Permendiknas) nomor 70 Tahun 2009 menyebutkan bahwa pendidikan inklusi sebagai sistem penyelenggaraan pendidikan yang memberikan kesempatan kepada semua peserta didik yang memiliki kelainan dan memiliki potensi kecerdasan dan/atau bakat istimewa untuk mengikuti pendidikan atau pembelajaran dalam lingkungan pendidikan secara bersama-sama dengan peserta didik pada umumnya. Hildegun Olsen dalam Tarmansyah, (2007: 82) pendidikan inklusi merupakan pendidikan dimana sekolah harus mengakomodasi semua anak tanpa memandang kondisi fisik, intelektual, sosial emosional, linguistik atau kondisi lainnya termasuk anak-anak penyandang cacat, dan berbakat. Dari paparan pendidikan inklusi di atas, maka pendidikan inklusi adalah pendidikan yang ditujukan bagi seluruh peserta didik baik yang memiliki kelainan dan memiliki potensi kecerdasan dan/atau bakat istimewa untuk mengikuti pendidikan atau pembelajaran dalam lingkungan pendidikan yang sama secara bersama-sama dengan peserta didik pada umumnya. Pada Konferensi Dunia tentang Pendidikan Berkebutuhan Khusus yang diadakan UNESCO, (1994) menghasilkan Pernyataan Salamanca yang menyatakan bahwa pendidikan inklusi merupakan perkembangan pelayanan pendidikan terkini dari model pendidikan bagi anak berkebutuhan khusus, dengan prinsip mendasar dari pendidikan inklusi, selama memungkinkan, semua peserta didik seyogyanya belajar bersama-sama tanpa memandang kesulitan ataupun perbedaan yang mungkin ada pada mereka. Hal ini membuat peneliti tertarik untuk menganalisis lebih dalam mengenai penerapan pendidikan inklusi di SDN Bromantakan 56 Surakarta dan bagaimana sekolah menangani kendala dan kekurangan dalam penerapan pendidikan inklusi.

\section{Rumusan Masalah}

Merujuk dari penjelasan tersebut semua anak termasuk anak berkebutuhan khusus berhak mendapatkan pendidikan, bersama-sama dengan siswa pada umumnya. Anak berkebutuhan khusus sama seperti anak pada umumnya, namun mereka memiliki karakteristik yang berbeda dengan anak-anak reguler. Hal ini yang membuat anak berkebutuhan khusus memiliki kebutuhan belajar yang berbeda dengan anak pada umumnya. Anak Berkebutuhan khusus bukan hanya anak yang mengalami hambatan pada intelektualnya saja namun juga anak-anak dengan hambatan fisik, sosial dan emosi, serta termasuk anak-anak dengan bakat dan kecerdasan istimewa. Choiri dan Yusuf (2009:8) mengemukakan klasifikasi anak berkebutuhan khusus yaitu anak tunanetra, anak tunarungu, anak tunagrahita, anak tunadaksa, anak tunalaras, anak berkesulitan belajar, anak gangguan perilaku, anak berbakat, anak autis, serta anak lamban belajar. Penerapan kurikulum untuk anak berkebutuhan khusus di sekolah reguler haruslah disesuaikan dengan karakteristik dan kebutuhan anak 
Arum Serla K, Widyastono H, Sunardi : Pendidikan Inklusi Sebagai Solusi Pendidikan Untuk Semua (Penerapan Pendidikan Inklusi di SDN Bromantakan 56 Surakarta)

\section{Tujuan Penelitian}

Di Indonesia penerapan program pendidikan inklusi belum maksimal, termasuk di Surakarta yang sudah mencanangkan diri menjadi kota inklusi sejak tahun 2013. Seiring berjalannya waktu, pelaksanaan pendidikan inklusi disekolah-sekolah yang ditunjuk sebagai sekolah inklusi oleh pemerintah daerah Surakarta mengalami banyak kendala. Kendala tersebut juga dirasakan oleh SDN Bromantakan 56 Surakarta. Sejak diturunkannya SK dari pemerintah daerah untuk ditunjuk sebagai sekolah inklusi SDN Bromantakan 56 mengalami kendala dalam penyelenggaraan pendidikan inklusi di sekolahnya. Mulai dari kesulitannya guru dalam pelaksanaan pembelajaran dikelas dengan anak berkebutuhan khusus di dalamnya sampai pada sarana prasarana yang kurang memadai dalam penerapan pendidikan inklusi di sekolah.

\section{METODE PENELITIAN}

Penelitian ini menggunakan penelitian kualitatif dengan jenis penelitian kualitatif studi kasus. Penelitian kualitatif adalah prosedur penelitian yang menghasilkan data deskriptif berupa kata-kata tertulis atau lisan dari orang-orang dan perilaku yang dapat diamati (Bogdan dan Taylor dalam Moleong 2007: 4). Jenis penelitian studi kasus dipilih karena tujuan penelitian adalah mengetahui penerapan pendidikan inklusi di SDN Bromantakan 56 Surakarta secara mendalam. Teknik pengumpulan data dalam penelitian ini menggunakan wawancara mendalam, observasi dan studi dokumentasi. Sementara itu, teknik analisis data dalam penelitian menggunakan teknik analisis interaktif dengan tahapan dimulai dari pengumpulan data, reduksi data, penyajian data, verifikasi dan penarikan kesimpulan.

\section{HASIL DAN PEMBAHASAN}

Hasil penelitian ini dibagi dalam beberapa tema untuk mempermudah pendeskripsian hasil penelitian yang terdiri dari landasan penyelenggaraan pendidikan inklusi, kurikulum yang digunakan, pendidik dan tenaga kependidikan,sarana dan prasarana pendidikan inklusi, sistem penerimaan $\mathrm{ABK}$, pengelolaan kegiatan belajar mengajar, proseder penilaian serta keadaan lingkungan sekolah inklusi. selain itu dalam pembahasan masing-masing subtema akan dijelaskan pula usaha yang dilakukan dan dapat dijadikan alternatif pemecahan masalah.

\section{Landasan Penyelenggaraan Pendidikan Inklusi Di SDN Bromantakan 56 Surakarta}

Pendidikan Inklusi berdasarkan landasan yuridis internasional didasarkan pada Deklarasi Salamanca (UNESCO, 1994) oleh para menteri pendidikan sedunia. Deklarasi ini adalah penegasan kembali atas deklarasi lanjutan yang berujung pada Peraturan Standar PBB tahun 1993 tentang kesempatan yang sama bagi individu penyandang cacat memperoleh pendidikan sebagai bagian integral dari sistem pendidikan yang ada. Deklarasi Salamanca menekankan bahwa selama memungkinka, semua anak harus belajar bersama-sama tanpa memandang perbedaan yang ada. Selain itu Pendidikan Inklusi di SDN Bromantakan didasarkan oleh terbitnya SK Walikota Surakarta No 25-A Tahun 2014 Tentang penyelenggaraan Pendidikan Inklusif yang menunjuk secara resmi SDN Bromantakan 56 sebagai salah satu sekolah dasar penyelenggara pendidikan inklusi. Selain SK walikota tersebut, pendidikan inklusi di SDN Bromantakan 56 Surakarta adalah Undang-Undang Nomor 20 Tahun 2003 tentang Sistem Pendidikan Nasional dan Permendiknas nomor 70 Tahun 2009 Tentang Pendidikan Inklusif bagi Peserta Didik yang Memiliki Potensi Kecerdasan dan/atau Bakat Istimewa. 
Arum Serla K, Widyastono H, Sunardi : Pendidikan Inklusi Sebagai Solusi Pendidikan Untuk Semua (Penerapan Pendidikan Inklusi di SDN Bromantakan 56 Surakarta)

\section{Kurikulum Pendidikan yang Digunakan}

Pada penerapan pendidikan inklusi seyogyanya kurikulum yang digunakan bagi siswa disesuaikan dengan keadaan yang dimiliki siswa. Siswa dalam sebuah kelas inklusi akan memiliki keberagaman kemampuan dan cara belajar. Anak berkebutuhan khusus membutuhkan dukungan pembelajaran tambahan dalam konteks kurikulum reguler, bukan kurikulum yang berbeda. Dalam Permendiknas Nomor 70 Tahun 2009 pasal 8 menyebutkan bahwa pembelajaran pada pendidikan inklusif mempertimbangkan prinsip-prinsip pembelajaran yang disesuaikan dengan karakteristik belajar peserta didik. Hal ini menuntut guru harus mampu mengembangkan perangkat pembelajaran pada Sekolah Inklusi termasuk guru SDN Bromantakan 56 Surakarta. Penyajian isi materi pada pembelajaran harus memanfaatkan berbagai sumber belajar agar dapat mengakomodasi pembelajaran bagi seluruh peserta didik termasuk anak berkebutuhan khusus didalamnya. Berdasarkan hasil wawancara dan observasi semua siswa di sekolah SDN Bromantakan 56 Surakarta menggunakan kurikulum 2013 dengan beberapa kali disesuaikan agar kebutuhan ABK dapat diakomodasi dengan baik. Kurikulum yang digunakan dirancang dari Standar Kompetensi dan Kompetensi Dasar (SK-KD) dari Badan Standar Nasional Pendidikan (BSNP). SK-KD tersebut disusun oleh masing-masing guru kelas dan guru mata pelajaran menjadi program tahunan, program semester, program pembelajaran, silabus, dan rencana pelaksanaan pembelajaran (RPP).

\section{Pendidik dan Tenaga Kependidikan}

Pendidik dan tenaga kependidikan harus memiliki kualifikasi akademik dan kompetensi yang cukup sebagai seorang pendidik. Kualifikasi akademik adalah tingkat pendidikan minimal yang harus dipenuhi oleh seorang pendidik yang dibuktikan dengan ijazah dan/atau sertifikat keahlian yang relevan sesuai ketentuan perundang-undangan yang berlaku. Kompetensi sebagai agen pembelajaran pada jenjang pendidikan dasar dan menengah serta pendidikan anak usia dini meliputi, kompetensi pedagogik; kompetensi kepribadian; kompetensi profesional; dan kompetensi sosial. Untuk memenuhi kompetensi tersebut tenaga pendidik dan kependidikan selain memiliki ijazah juga akan mengikuti beberapa pelatihan, seminar atau pembekalan terkait penerapan pendidikan inklusi di sekolah. Selain guru-guru kelas yang mengajar siswa dengan modifikasi pembelajaran yang disesuaikan dengan kebutuhan anak. Di SDN Bromantakan 56 Surakarta juga terdapat guru pendamping khusus lulusan pendidikan luar biasa. Dimana itu menandakan bahwa guru pendamping khusus tersebut memiliki kualifikasi yang baik dalam menangani ABK. Di SDN Bromantakan 56 Surakarta seluruh program pendidikan dilaksanakan, diatur, dan diawasi serta dievaluasi oleh guru pendamping khusus tersebut. Selain itu, guru kelas dan guru pendamping khusus di SDN Bromantakan 56 Surakarta sering mengikuti pelatihan atau seminar terkait pendidikan inklusi yang diadakan oleh berbagai instansi.

\section{Sarana dan Prasarana}

Sarana dan prasarana merupakan hal vital dalam penerapan pendidikan inklusi. sarana dan prasarana memiliki peran penting dalam terwujudnya pendidikan inklusi yang baik di lingkungan sekolah. Gedung sekolah SDN Bromantakan 56 Surakarta merupakan gedung SMPN 5 Surakarta. Hal ini berarti SDN Bromantakan 56 Surakarta masih menumpang gedung pada sekolah lain. Kemudian, karena terkendala gedung yang berbagi dengan SMPN 5 Surakarta, aksesibilitas di SDN Bromantakan 56 Surakarta belum dapat mengakomodasi seluruh peserta didik, khususnya siswa dengan kebutuhan khusus (ABK). Tidak ada kelas khusus yang digunakan apabila dibutuhkan tambahan jam belajar atau program remedial bagi anak berkebutuhan khusus. Namun demikian, terkait dengan alat bantu belajar dalam proses pembelajaran di kelas sejak dicanangkan sebagai sekolah inklusi melalu SK walikota 
Arum Serla K, Widyastono H, Sunardi : Pendidikan Inklusi Sebagai Solusi Pendidikan Untuk Semua (Penerapan Pendidikan Inklusi di SDN Bromantakan 56 Surakarta)

fasilitas yang ada tergolong lengkap. Pemerintah kota secara berkala memberikan bantuan operasional penunjang pembelajaran dalam kelas bagi $\mathrm{ABK}$.

\section{Sistem Penerimaan Anak Berkebutuhan Khusus}

Salah satu hal penting dalam penyelenggaraan pendidikan adalah rekruitmen atau penerimaan peserta didik baru. Rekruitmen seleksi ABK di SDN Bromantakan 56 Surakarta mengharuskan anak berkebutuhan khusus menyertakan hasil identifikasi dan asessment dari psikolog yang menandakan bahwa ABK tersebut mampu dalam segi sosial, perilaku, mental dan akademik untuk berada di sekolah inklusi. Untuk selanjutnya guru pendamping khusus mengidentifikasi lebih lanjut kebutuhan-kebutuhan apa yang diperlukan ABK dalam pembelajaran melalui PPI.

Tabel 1 Daftar ABK di SDN Bromantakan 56 Tahun Ajaran 2019/2020

\begin{tabular}{|c|c|c|c|c|c|c|}
\hline \multirow[t]{2}{*}{ Ketunaan } & \multicolumn{6}{|c|}{ Kelas } \\
\hline & 1 & 2 & 3 & 4 & 5 & 6 \\
\hline \multicolumn{7}{|l|}{ Tunanetra } \\
\hline Tunarungu & 2 & & & & & 1 \\
\hline Tunagrahita & 1 & & & & & 1 \\
\hline \multicolumn{7}{|l|}{ Tunadaksa } \\
\hline Tunalaras & & & 1 & & 1 & \\
\hline Autis & & 1 & 1 & & & \\
\hline ADHD & & 1 & & & & \\
\hline Slow learner & 1 & 1 & 2 & 2 & & 1 \\
\hline Tunaganda & & 1 & & & & \\
\hline jumlah & 4 & 4 & 4 & 2 & 1 & 3 \\
\hline
\end{tabular}

\section{Pengelolaan Kegiatan Belajar Mengajar}

Menurut Agustyawati dan Solicha (2009: 100), pendidikan inklusi memiliki beberapa model, yaitu : Kelas Reguler (Inklusi Penuh), dimana anak berkebutuhan khusus belajar bersama anak non berkebutuhan khusus sepanjang hari di kelas reguler dengan menggunakan kurikulum yang sama. Kelas Reguler dengan Cluster, model ini membuat anak berkebutuhan khusus belajar bersama anak non berkebutuhan khusus di kelas reguler dalam kelompok khusus. Kelas Reguler dengan Pull Out, dimana anak berkebutuhan khusus belajar bersama anak reguler di kelas reguler namun dalam waktu-waktu tertentu ditarik dari kelas reguler ke ruang lain untuk belajar dengan guru pembimbing khusus. Kelas Reguler dengan Cluster dan Pull Out, dalam model ini anak berkebutuhan khusus belajar bersama anak non berkebutuhan khusus di kelas reguler dalam kelompok khusus, dan dalam waktuwaktu tertentu ditarik dari kelas reguler ke ruang lain untuk belajar dengan guru pembimbing khusus. Kelas Khusus dengan Berbagai Pengintegrasian, anak berkebutuhan khusus belajar di dalam kelas khusus pada sekolah reguler, namun dalam bidang-bidang tertentu dapat belajar bersama anak lainnya di kelas reguler. Kelas Khusus Penuh, anak berkebutuhan khusus belajar di dalam kelas khusus pada sekolah reguler. Dari berbagai macam model tersebut pengelolaan proses belajar di SDN Bromantakan 56 Surakarta dilakukan tergantung kebutuhan ABK, apabila ia mampu mengikuti pembelajaran secara penuh maka ia akan selalu berada di dalam kelas saat pembelajaran mengikuti wali kelas, namun bila ia menunjukan gejala perilaku yang tidak sesuai (tantrum) atau anak tidak mampu mengkuti materi pembelajaran maka GPK menggunan sistem pull out. 
Arum Serla K, Widyastono H, Sunardi : Pendidikan Inklusi Sebagai Solusi Pendidikan Untuk Semua (Penerapan Pendidikan Inklusi di SDN Bromantakan 56 Surakarta)

\section{Proses Penilaian}

Penilaian dalam dunia pendidikan merupakan titik akhir dari keberlangsungan pembelajaran. Sistem penilain ABK di SDN Bromantakan 56 Surakarta tidak diatur secara resmi oleh pemerintah pusat melainkan diserahkan kepada otoritas sekolah. SDN Bromantakan 56 Surakarta menggunakan sistem penilaian pada ABK dengan ketentuan apabila anak sudah mampu mencapai minimal 50\% indikator dari PPI yang dibuat GPK maka anak bisa naik kelas namun bila tidak mencapai maka akan diadakan remedial agar anak bisa naik kelas.

\section{Lingkungan Masyarakat}

Lingkungan masyarakat akan sangat berpengaruh dalam proses pembelajaran. Lingkungan sekitar SDN Bromantakan 56 Surakarta sangat proaktif terhadap ABK. Hal ini ditunjukan dari partisipasi mereka dalam berbagai acara sekolah yang melibatkan ABK tanpa membedabedakan anak-anak tersebut. Mereka juga sudah paham dengan perilaku dan kebutuhan ABK yang ada di SDN Bromantakan 56 Surakarta, serta ikut mendukung juga membantu mereka dalam bersosalisasi. Seperti telah dijelaskan di atas, program pendidikan inklusi di SDN Bromantakan 56 Surakarta telah terselenggara dengan cukup baik. Namun, dalam penerapannya tetap mengalami kendala. Salah satunya adalah pada kebijakan kurikulum. Belum adanya kebijakan pemerintah dalam pembuatan kurikulum khusus untuk ABK di sekolah inklusi membuat SDN Bromantakan 56 Surakarta menggunakan kurikulum 2013 yang dimodifikasi sendiri oleh guru untuk diakomodasikan pada peserta didik berkebutuhan khusus. Pemerintah menyerahkan sepenuhnya kepada sekolah terkait kurikulum bagi ABK yang bersekolah disana. Hal ini memberikan kesan bahwa pihak sekolah tidak mempersiapkan sekolah untuk menjadi pelaksana kebijakan pendidikan inklusi yang sesuai dengan standar pemerintah. Masalah lain timbul dari sisi sarana dan prasarana, di SDN Bromantakan 56 Surakarta yang belum memenuhi standar yang ditetapkan pemerintah untuk sekolah inklusi. Meskipun pemerintah daerah secara berkala memberikan bantuan operasional untuk sarana dan prasarana pembelajaran ABK, namun tetap ada kendala. Seperti yang sudah dijelaskan, gedung sekolah yang masih bersamaan dengan SMPN 5 Surakarta sangat tidak aksesibel dalam mengakomodasi anak berkebutuhan khusus yang bersekolah disana. ABK dengan karakteristik yang berbeda-beda seharusnya mendapat aksesibilitas dan fasilitas yang mempermudah dalam mengikuti proses pembelajaran di kelas maupun kegiatan di luar kelas. Peneliti berasumsi bahwa SDN Bromantakan 56 Surakarta adalah sekolah inklusi yang ditunjuk secara langsung oleh pemerintah kota dengan diturunkannya SK Walikota No 25-A Tahun 2014 Tentang penyelenggaraan Pendidikan Inklusi seharusnya tidak mengalami kendala dalam hal kurikulum untuk ABK. Seharusnya sekolah sudah memenuhi berbagai syarat dan kriteria yang cukup terkait dengan kebutuhan sekolah dalam menerapkan sekolah inklusi dengan baik. Sarana dan prasarana di sekolah juga sudah menunjang proses penerapan kebijakan pendidikan inklusi. Hasil penelitian ini menunjukkan hal tersebut belum terpenuhi secara sempurna. Hal ini mungkin dikarenakan belum tersedianya kebijakan-kebijakan yang mengatur secara tegas penerapan program pendidikan inklusi. Hasil penelitian menunjukkan meskipun SDN Bromantakan 56 Surakarta telah melaksanakan dan menerapkan program pendidikan inklusi di sekolah dan sudah maksimal mengusahakan pelaksanaan pendidikan inklusi dengan baik, namun tanpa perhatian dari pemerintah pusat sekolah belum akan mampu menjadi sekolah inklusi yang sesuai dengan tuntutan masyarakat

\section{KESIMPULAN}

Berdasarkan analisis dan pembahasan data yang diperoleh dari penelitian ini, di SDN Bromantakan 56 Surakarta sudah berusaha mewujudkan program pendidikan inklusi disekolahnya. Sekolah berlandaskan SK Walikota Nomor 25-A tentang Penyelenggaraan 
Arum Serla K, Widyastono H, Sunardi : Pendidikan Inklusi Sebagai Solusi Pendidikan Untuk Semua (Penerapan Pendidikan Inklusi di SDN Bromantakan 56 Surakarta)

Pendidikan Inklusi mampu mengembangkan sekolah inklusi dengan maksimal. Dalam hal ini pemerintah memberikan kebebasan sepenuhnya kepada pihak sekolah untuk memodifikasi sendiri kurikulum yang ada agar disesuaikan pada ABK yang bersekolah di sekolah tersebut. Sekolah memakai kurikulum 2013 untuk menjadi pedoman dalam pemberian materi pembelajaran kepada seluruh siswa termasuk ABK, tidak ada kurikulum khusus atau kurikulum termodifikasi untuk ABK sesuai dengan kebutuhan dan karateristik masing-masing anak. Selain itu, tantangan lain yang ada di SDN Bromantakan 56 Surakarta adalah sarana dan prasarana yang ada di sekolah. Seperti yang sudah dijelaskan, gedung sekolah yang masih bersamaan dengan SMPN 5 Surakarta sangat tidak aksesibel dalam mengakomodasi anak berkebutuhan khusus yang bersekolah disana. ABK dengan karakteristik yang berbeda-beda seharusnya mendapat aksesibilitas dan fasilitas yang mempermudah dalam mengikuti proses pembelajaran di kelas maupun kegiatan di luar kelas.

\section{DAFTAR PUSTAKA}

Agustyawati \& Solicha. (2009). Psikologi Pendidikan Anak Berkebutuhan Khusus. Jakarta: Lembaga Penelitian UIN Jakarta.

Coiri, A. S \& Yusuf, M. (2009). Pendidikan Anak Berkebutuhan Khusus Secara Inklusif. Surakarta: Inti Media Surakarta.

Erawati, dkk. (2016). Pendidikan Karakter Bangsa pada Anak Berkebutuhan Khusus dalam Pendidikan Inklusif. Jurnal Studi Sosial. Vol 4. No 1. 20-29.

Mayasari. (2016). Implementasi Kurikulum 2013 pada Anak Berkebutuhan Khusus (ABK): Studi Kasus SD Muhammadiyah Sapen Yogyakarta. Inklusi:Journal of Disability Studies. Vol 3. No.1. 1-18.

Moleong, L. J. (2007). Metodologi Penelitian Kualitatif. Bandung: PT Remaja Rosdakarya. Permendiknas nomor 70 tahun 2009 tentang Pendidikan Inklusif bagi Peserta Didik yang Memiliki Potensi Kecerdasan dan/atau Bakat Istimewa.

Stubb, S. (2008). Inclusive Edication Where There are Few Resources. Norway: The Atlas Alliance.

Tarmansyah.(2007). Inklusi Pendidikan untuk Semua. Jakarta: Depdiknas.

Undang-Undang Nomor 20 Tahun 2003 tentang Sistem Pendidikan Nasional. 